\title{
VIRUS RESPIRATORIOS Y CARACTERÍSTICAS CLÎNICO-EPIDEMIOLÓGICAS EN LOS EPISODIOS DE INFECCIÓN RESPIRATORIA AGUDA
}

\author{
Yaquelina Chirinos-Saire (1,a, Robert Reyna-García@1,a, Emilio Aguilar-Huauya®1,b, \\ Carlos Santillán-Salas (iD 1,c \\ ${ }^{1}$ Instituto Nacional de Salud del Niño San Borja, Lima, Perú. \\ ${ }^{a}$ Tecnólogo médico en Laboratorio Clínico y Anatomía Patológica; ${ }^{\mathrm{b}}$ médico especialista en Patología Clínica; ${ }^{\mathrm{c}}$ médico \\ especialista en Infectología.
}

\section{RESUMEN}

Con el objetivo de determinar la frecuencia viral y las características clínico-epidemiológicas en los episodios de infección respiratoria aguda de pacientes del Instituto Nacional de Salud del Niño San Borja en Lima, se analizó la información de los episodios de pacientes que requirieron al menos una prueba de inmunofluorescencia directa desde el 1 de enero del 2017 al 31 de diciembre del 2018. Se identificaron 1153 episodios en 707 pacientes. La mediana de la edad fue de 1 año y el 55\% fueron del sexo masculino. La frecuencia viral fue del 13,4\%; el virus respiratorio sincitial se identificó en el 10,7\% de los episodios. La frecuencia viral fue mayor en los menores de 1 año (16,2\%); en aquellos con enfermedad congénita respiratoria $(38,9 \%)$ y durante el otoño $(24,2 \%)$. Los síntomas más comunes fueron tos $(70,3 \%)$ y fiebre (53,4\%); y los principales diagnósticos fueron neumonía viral $(31,8 \%)$ y bronquiolitis $(23,4 \%)$. Se concluye que la frecuencia viral respiratoria estuvo relacionada con la edad, estacionalidad y patología preexistente.

Palabras claves: Pediatría; Infecciones Respiratorias; Frecuencia; Virus; Técnica de Inmunofluorescencia Directa; Perú (fuente: DeCS BIREME).

\section{RESPIRATORY VIRUSES AND CLINICAL- EPIDEMIOLOGICAL CHARACTERISTICS IN EPISODES OF ACUTE RESPIRATORY INFECTION}

\begin{abstract}
The aim of the study was to determine the viral frequency and clinical-epidemiological characteristics in the episodes of acute respiratory infection in patients of the Instituto Nacional de Salud del Niño San Borja in Lima, the information of the episodes of patients who required at least one direct Immunofluorescence test from January 1, 2017 to December 31, 2018 was analyzed. 1153 episodes were identified in 707 patients. The median age was 1 year and $55 \%$ were male. The viral frequency was $13.4 \%$; respiratory syncytial virus was identified in $10.7 \%$ of the episodies. The viral frequency was higher in children under 1 year of age (16.2\%); in those with congenital disease respiratory (38.9\%) and during the autumn (24.2\%). The most common symptoms were cough (70.3\%) and fever (53.4\%); and the main diagnoses, viral pneumonia (31.8) and bronchiolitis (23.4\%). It is concluded that the respiratory viral frequency was related to age, seasonality and pre-existing pathology.
\end{abstract}

Citar como: Chirinos-Saire Y, Reyna-García R, Aguilar-Huauya E, Santillán-Salas C. Virus respiratorios y características clínico-epidemiológicas en los episodios de infección respiratoria aguda. Rev Peru Med Exp Salud Publica. 2021;38(1):101-7. doi: https://doi. org/10.17843/rpmesp.2021.381.6346

Correspondencia: Yaquelina ChirinosSaire; Servicio de Patología Clínica, INSN-SB, Av. Agustín de la Rosa Toro 1399, Urb. Jacaranda II - San Borja, Lima,Perú; yaquy_cs@hotmail.com

Recibido: $18 / 08 / 2020$ Aprobado: 02/12/2020 En línea: 01/02/2021
Keywords: Pediatrics; Respiratory Infections; Frequency; Viruses; Fluorescent Antibody Technique, Direct; Peru (source: MeSH NLM).

\section{INTRODUCCIÓN}

Las infecciones respiratorias agudas (IRA) se encuentran entre las tres primeras causas de morbimortalidad en la población general, y primera causa de mortalidad en menores de cinco años, principalmente en países en vías de desarrollo ${ }^{(1,2)}$. El $80 \%$ a $90 \%$ de las IRA son de etiología $\operatorname{viral}^{(3)}$, las infecciones de las vías respiratorias altas son las de mayor frecuencia. Sin embargo, las neumonías son las que representan un mayor problema para la salud pública ${ }^{(1,4)}$.

En el Perú, durante el 2018 la tasa de incidencia acumulada de episodios de IRA fue 9297 por 10000 niños menores de cinco años y de neumonía fue de 100 por 10000 menores de cinco años, ambos con una tendencia al descenso en los últimos años; mientras la tasa de 
letalidad (1,0 muertes por 100 episodios de neumonía) se ha mantenido constante ${ }^{(5)}$.

Estudios realizados en el extranjero, muestran una frecuencia de virus respiratorios (VR) en pacientes pediátricos entre el $34,1 \%$ a $76,7 \%{ }^{(6-9)}$, en el Perú se reportó entre $33,5 \%$ a $49,7 \%{ }^{(10,11)}$. Actualmente, en nuestro país no existe información detallada sobre la frecuencia de infecciones virales en niños con comorbilidades. Adicionalmente, no existen estudios que comparen la frecuencia de estas infecciones entre pacientes hospitalizados y ambulatorios, ni su tendencia estacionaria que contribuyan a establecer estrategias óptimas de vigilancia, prevención y control en estas infecciones.

El presente estudio, tiene por objetivo describir la frecuencia en la detección de virus respiratorios y las características clínico-epidemiológicas de los episodios de IRA en niños atendidos en los distintos servicios del Instituto Nacional de Salud del Niño San Borja (INSN-SB), centro de referencia nacional para el manejo de enfermedades complejas pediátricas, durante el 2017-2018.

\section{EL ESTUDIO}

\section{Diseño y población de estudio}

Se realizó un estudio descriptivo, retrospectivo y transversal. Se recopiló información laboratorial de los episodios de IRA de pacientes a quienes se les realizó la prueba de inmunofluorescencia directa (IFD) para VR, quienes procedieron de los diferentes servicios del INSN-SB del 1 de enero del 2017 al 31 de diciembre del 2018. Se incluyeron todos los episodios de IRA de pacientes: a) de 0 a 18 años, b) internados o ambulatorios, c) con toma de muestra por hisopado nasofaríngeo (HNF). Se excluyeron episodios de IRA de pacientes: a) externos de la institución, b) con reporte de muestra inadecuada.

La IRA fue definida por la presencia de uno o más síntomas como tos, rinorrea, obstrucción nasal, odinofagia, otalgia, sibilancias o dificultad respiratoria, acompañados o no de fiebre. Un episodio de IRA estuvo comprendido entre el primer día de inicio de la sintomatología hasta el decimocuarto día.

\section{Procedimientos}

La prueba de IFD para VR fue realizada como parte de la atención institucional habitual; a través del Servicio de Patología Clínica se tomaron muestras de HNF, obtenidas con hisopos flocados estériles y colocados en un medio de transporte viral. Las muestras se transportaron y almacenaron a una temperatura entre 2 a $8^{\circ} \mathrm{C}$ hasta su procesamiento; siguiendo el protocolo de trabajo del kit comercial $D^{3}$ Ultra $8^{{ }^{m}}$ DFA Respiratory Virus Screening \& Identification, para la detección de ocho tipos de VR: adenovirus (ADV), virus de la influenza A (Flu-A) y B (Flu-B), virus de la parainfluenza (PIV) 1, 2 y 3, metapneumovirus (hMPV) y virus sincitial respiratorio (VRS).

\section{MENSAJES CLAVE}

Motivación para realizar el estudio: En Perú, son escasos los estudios que evalúan la frecuencia de infecciones virales en niños con comorbilidades y su perfil epidemiológico y clínico.

Principales hallazgos: La detección viral fue del 13,4\% en los episodios de infección respiratoria aguda, el virus respiratorio sincitial fue el patógeno más común; la frecuencia viral fue mayor en los niños menores de 1 año con enfermedades congénitas respiratorias y durante el otoño.

Implicancias: La caracterización clínica y epidemiológica en los pacientes susceptibles a las infecciones respiratorias virales permitirá definir mejor las estrategias de vigilancia, prevención y control hospitalario.

La lectura de las muestras fue realizada en el microscopio de fluorescencia Axio Scope.A1 de la marca ZEISS; se consideró muestra adecuada la observación de al menos 20 células epiteliales columnares en el total de campos de lectura. Un resultado positivo para VR estuvo definido por la observación de al menos dos células con fluorescencia intracelular verde manzana, en el total de campos de lectura.

Las variables en el estudio fueron edad, sexo, año de atención médica, tipo de atención hospitalaria, estacionalidad, patología de base, diagnóstico clínico actual, sintomatología, tipo de VR y coinfección viral.

Los datos de cada episodio de IRA se recolectaron a partir de la revisión de historias clínicas, fichas epidemiológicas y del sistema informático hospitalario. La información obtenida fue ingresada a una hoja de cálculos en el programa Microsoft Excel 2016.

\section{Análisis estadístico}

Se utilizó el programa Stata versión 15. La variable numérica edad presentó una distribución asimétrica y fue resumida con la mediana y el rango intercuartílico (RIC). Las variables categóricas fueron presentadas como frecuencias absolutas y relativas. Los datos fueron mostrados en tablas y figuras. La comparación para las variables categóricas fue realizada con la prueba de Chi cuadrado, y para las variables numéricas se usó la prueba de U de Mann Whitney. Un valor de p <0,05 fue considerado como estadísticamente significativo.

\section{Aspectos éticos}

El presente estudio fue aprobado por el Comité de Ética en Investigación del INSN-SB. La información recolectada permaneció en absoluta confidencialidad y su uso fue exclusivo para el estudio. 


\section{HALLAZGOS}

Durante el periodo de estudio, se hallaron 1153 episodios de IRA en 707 pacientes con solicitud de una prueba de IFD para VR (1,6 episodios por paciente). El análisis estadístico se basó en los episodios de IRA, así la frecuencia de detección viral fue del 13,4\% (154/1153) siendo variable entre los dos años de estudio y para cada tipo de virus ( $0,0 \%$ a $12,3 \%)$. No se detectaron ADV ni Flu-B (Tabla 1). De los episodios con VR positivos ( $\mathrm{n}=154)$, la distribución fue de $7,1 \%$ para Flu-A; $7,7 \%$ para hMPV; 5,2\% para PIV (1-3) y $80 \%$ para VRS. No se halló ningún caso de coinfección viral.

Del total de episodios de IRA, la mediana de edad fue de 1 año (RIC: $0-5$ ); las edades fueron categorizadas en cuatro grupos, el 36,8\% de los episodios se registraron en los menores de 1 año, quienes tuvieron una mayor frecuencia viral (16,2\%). Hubo diferencias estadísticamente significativas entre grupo etario y la frecuencia viral (Tabla 2). El 55,9\% $(\mathrm{n}=645)$ de los episodios fueron en hombres con una frecuencia viral del $12,1 \%$ y en mujeres $(n=519)$ fue del $14,8 \%$, sin diferencias significativas $(\mathrm{p}=0,181)$.

La frecuencia viral en el 2017 fue del 10,2\% y en el 2018 del $15,8 \%$, siendo esta diferencia significativa $(p=0,006)$. De los episodios con VR positivos, el VRS fue el más prevalente en ambos años ( $84,6 \%$ y $77,5 \%$, respectivamente); la frecuencia de hMPV fue de $11,8 \%$ en el 2018 en comparación al 0,0\% del 2017 (Tabla 3). El 72,6\% del total de episodios de IRA fueron de hospitalización; quienes tuvieron una frecuencia viral del 14,1\%, similar a los procedentes del servicio de Emergencia con 14,4\% pero diferente a los procedentes de consultorios con 7,0\% (Tabla 2).

Los episodios de IRA fueron más frecuentes durante las estaciones de invierno y otoño; la mayor frecuencia viral se dio en otoño $(24,2 \%)$, hubo diferencias significativas entre las estaciones $(\mathrm{p}<0,001)$. Entre los meses de febrero y abril del 2017, y mayo y julio del 2018 se registró la mayor frecuencia viral entre $20,7 \%$ a $25,5 \%$ y $41,6 \%$ a $21,6 \%$, respectivamente (Figura 1). Durante el verano, otoño e invierno, el VRS fue el principal patógeno; mientras que en primavera lo fue el hMPV (Tabla 3).
Del total de episodios de IRA, el 96,3\% registró una patología de base, la neoplasia hematológica $(\mathrm{NH})$ y la enfermedad congénita del sistema circulatorio (EC-SC) fueron las más frecuentes con un $31,9 \%$ y $25,1 \%$, respectivamente. La frecuencia viral fue mayor en los casos con enfermedad congénita del aparato respiratorio (EC-AR) $(38,9 \%)$ y malformación congénita del sistema osteomuscular (MC-SO) $(35,7 \%)$, hubo diferencias significativas entre las patologías preexistentes $(\mathrm{p}<0,001)$ (Tabla 2).

Entre los episodios con detección viral, los diagnósticos clínicos más frecuentes fueron neumonía viral $(31,8 \%)$ y bronquiolitis $(23,4 \%)$. En los episodios con bronquiolitis, el VRS fue identificado en el 88,9\%; en los de neumonía, el VRS y el hMPV estuvieron en el 79,6\% y 14,3\%, respectivamente (Tabla 3). Las manifestaciones clínicas más frecuentes en $148 / 154$ episodios fueron tos $(70,3 \%)$, fiebre $(53,4 \%)$, rinorrea $(52,7 \%)$, disnea $(51,3 \%)$ y sibilancias $(50,7 \%)$.

\section{DISCUSIÓN}

En el presente estudio, la frecuencia de detección viral fue de 13,4\% entre todos los episodios de IRA identificados. Estudios publicados reportaron una prevalencia viral entre el $11,9 \%$ a $49,7 \%$ en pacientes pediátricos sin comorbilidades informadas y con detección viral por IFD ${ }^{(6,7,10,11)}$. Este estudio halló que las infecciones virales fueron más frecuentes en los menores de 1 año y en los menores de 5 años; para este último grupo etario, diferentes estudios reportaron una frecuencia viral entre $14,8 \%$ a $40 \%{ }^{(7,10,12)}$; esta variación porcentual pudo ser debida a una población infantil heterogénea, presencia o no de enfermedades subyacentes, diferentes ámbitos geográficos o distintas medidas de vigilancia y control en los establecimientos de atención médica.

La frecuencia viral en hospitalización fue similar a la obtenida en el servicio de Emergencia, y mayor al de los consultorios; observándose que los pacientes de hospitalización y Emergencia presentaron características similares en el grupo etario - los menores de 3 años representaron el 64\%-y en comorbilidad - principalmente casos de EC-SC-; mientras los de consultorio, fueron pacientes principalmente de

Tabla 1. Frecuencia de detección de virus respiratorios en los episodios de IRA de pacientes atendidos en el Instituto Nacional de Salud del Niño San Borja, 2017-2018.

\begin{tabular}{|c|c|c|c|c|c|c|c|c|}
\hline \multirow{3}{*}{ Año } & \multirow{2}{*}{$\begin{array}{l}\text { Episodios } \\
\text { con IRA }\end{array}$} & \multirow{2}{*}{$\begin{array}{l}\text { Episodios } \\
\text { con VR }(+)\end{array}$} & \multirow[b]{2}{*}{ Flu-A } & \multicolumn{3}{|c|}{ Virus respiratorios } & \multirow[b]{2}{*}{ PIV-3 } & \multirow[b]{2}{*}{ VRS } \\
\hline & & & & hMPV & PIV-1 & PIV-2 & & \\
\hline & $\mathbf{n}$ & n (\%) & n (\%) & n (\%) & n (\%) & n (\%) & n (\%) & n (\%) \\
\hline 2017 & 508 & $52(10,2)$ & $4(0,8)$ & $0(0,0)$ & $1(0,2)$ & $2(0,4)$ & $1(0,2)$ & $44(8,7)$ \\
\hline 2018 & 645 & $102(15,8)$ & $7(1,1)$ & $12(1,9)$ & $1(0,2)$ & $0(0,0)$ & $3(0,5)$ & $79(12,3)$ \\
\hline Total & 1153 & $154(13,4)$ & $11(0,9)$ & $12(1,0)$ & $2(0,2)$ & $2(0,2)$ & $4(0,4)$ & $123(10,7)$ \\
\hline
\end{tabular}

IRA: infección respiratoria aguda; VR: virus respiratorio; Flu-A: Influenza virus A; hMPV: Metapneumovirus; PIV: Parainfluenza virus; VRS: Virus respiratorio sincitial. 
Tabla 2. Características descriptivas en los episodios de IRA de pacientes atendidos en el Instituto Nacional de Salud del Niño San Borja, según la detección de virus respiratorios. 2017-2018.

\begin{tabular}{|c|c|c|c|c|c|c|}
\hline \multirow[t]{2}{*}{ Características } & \multirow{2}{*}{$\begin{array}{c}\begin{array}{c}\text { Episodios de } \\
\text { IRA } \\
(\mathbf{n}=1153)\end{array} \\
\mathbf{n}\end{array}$} & \multicolumn{2}{|c|}{$\begin{array}{l}\text { VR negativo } \\
(\mathrm{n}=999)\end{array}$} & \multicolumn{2}{|c|}{$\begin{array}{l}\text { VR positivo } \\
\quad(n=154)\end{array}$} & \multirow[t]{2}{*}{ Valor de $\mathrm{p}^{\mathrm{a}}$} \\
\hline & & $\mathbf{n}$ & $\%$ & n & $\%$ & \\
\hline Edad, mediana (RIC) & $1(0-5)$ & $2(0-6)$ & $(0-6)$ & $1(0-3)$ & $(0-3)$ & $<0,001^{\mathrm{b}}$ \\
\hline Grupo etario (años) & & & & & & 0,013 \\
\hline$<1$ & 425 & 356 & 83,8 & 69 & 16,2 & \\
\hline $1-4$ & 373 & 319 & 85,5 & 54 & 14,5 & \\
\hline $5-10$ & 271 & 245 & 90,4 & 26 & 9,6 & \\
\hline $11-18$ & 84 & 79 & 94,0 & 5 & 6,0 & \\
\hline Sexo & & & & & & 0,181 \\
\hline Femenino & 519 & 442 & 85,2 & 77 & 14,8 & \\
\hline Masculino & 634 & 557 & 87,9 & 77 & 12,1 & \\
\hline Año de atención & & & & & & 0,006 \\
\hline 2017 & 508 & 456 & 89,8 & 52 & 10,2 & \\
\hline 2018 & 645 & 543 & 84,2 & 102 & 15,8 & \\
\hline Tipo de atención & & & & & & 0,083 \\
\hline Hospitalización & 837 & 719 & 85,9 & 118 & 14,1 & \\
\hline Emergencia & 188 & 161 & 85,6 & 27 & 14,4 & \\
\hline Consultorio & 128 & 119 & 93,0 & 9 & 7,0 & \\
\hline Estacionalidad & & & & & & $<0,001$ \\
\hline Otoño & 347 & 263 & 75,8 & 84 & 24,2 & \\
\hline Verano & 160 & 144 & 90,0 & 16 & 10,0 & \\
\hline Invierno & 383 & 344 & 89,8 & 39 & 10,2 & \\
\hline Primavera & 263 & 248 & 94,3 & 15 & 5,7 & \\
\hline Patología de base & & & & & & $<0,001$ \\
\hline Aplasia medular & 48 & 48 & 100,0 & 0 & 0,0 & \\
\hline EC. aparato respiratorio & 18 & 11 & 61,1 & 7 & 38,9 & \\
\hline EC. sistema circulatorio & 289 & 240 & 83,0 & 49 & 17,0 & \\
\hline EC. sistema nervioso & 41 & 34 & 82,9 & 7 & 17,1 & \\
\hline MC. tracto digestivo & 41 & 33 & 80,5 & 8 & 19,5 & \\
\hline MC. sistema osteomuscular & 14 & 9 & 64,3 & 5 & 35,7 & \\
\hline E. aparato digestivo & 17 & 15 & 88,2 & 2 & 11,8 & \\
\hline E. sistema nervioso & 44 & 34 & 77,3 & 10 & 22,7 & \\
\hline E. sistema respiratorio & 43 & 39 & 90,7 & 4 & 9,3 & \\
\hline Neoplasias hematológicas & 368 & 339 & 92,1 & 29 & 7.9 & \\
\hline TPH-TOS & 66 & 59 & 89,4 & 7 & 10,6 & \\
\hline Otras enfermedades & 121 & 106 & 87,6 & 15 & 12,4 & \\
\hline Previamente sano & 43 & 32 & 74,4 & 11 & 25,6 & \\
\hline
\end{tabular}

IRA: Infección respiratoria aguda; VR: Virus respiratorio; E: Enfermedad; EC: Enfermedad congénita; MC: malformación congénita; TOS: trasplante de órganos sólidos; TPH: trasplante de progenitores hematopoyéticos.

${ }^{\text {a }}$ Prueba de Chi cuadrado; ${ }^{\text {b }}$ prueba de U de Mann Whitney

5 a 10 años y con patologías de NH o TPH. La detección viral más alta fue en otoño y la más baja en primavera; presentando el Flu-A y el VRS un pico de detección en otoño; el PIV en invierno y el hMPV en primavera; estos datos son concordantes con otros estudios en Sudamérica ${ }^{(8,10,13)}$.

Las infecciones virales, principalmente las causadas por VRS, pueden incrementar el riesgo de morbimortalidad en pacientes con cardiopatías congénitas, $\mathrm{NH}$, enfermedades respiratorias crónicas, malformaciones congénitas del aparato respiratorio y prematuridad. Los niños cardiópatas menores de 2 años presentan un mayor riesgo de desnutrición lo que los predispone a la adquisición de infecciones virales ${ }^{(14)}$.

Este estudio registró que el VRS fue el principal patógeno identificado, con una alta tasa de detección en los casos con ECAR (4/18) y con MC-SO (5/14); sin embargo, se considera que para un mejor análisis se debería contar con una muestra más 
Tabla 3. Características descriptivas en los episodios de IRA con detección viral en pacientes atendidos en el Instituto Nacional de Salud del Niño San Borja, según tipo de virus. 2017-2018.

\begin{tabular}{|c|c|c|c|c|c|c|c|c|c|}
\hline \multirow{2}{*}{ Características } & \multirow{2}{*}{$\begin{array}{c}\begin{array}{c}\text { Total VR }(+) \\
(n=154)\end{array} \\
n\end{array}$} & \multicolumn{2}{|c|}{$\begin{array}{l}\text { Flu- A } \\
(n=11)\end{array}$} & \multicolumn{2}{|c|}{$\begin{array}{l}\mathrm{hMPV} \\
(\mathrm{n}=12)\end{array}$} & \multicolumn{2}{|c|}{$\begin{array}{c}\text { PIV (1-3) } \\
(n=8)\end{array}$} & \multicolumn{2}{|c|}{$\begin{array}{c}\text { VRS } \\
(\mathrm{n}=123)\end{array}$} \\
\hline & & $\mathbf{n}$ & $\%$ & $\mathbf{n}$ & $\%$ & $\mathbf{n}$ & $\%$ & $\mathbf{n}$ & $\%$ \\
\hline Edad, mediana (RIC) & & $3(1-6)$ & & $1(0-1,5)$ & & $1,5(0,5-4,5)$ & & $1(0-3)$ & \\
\hline \multicolumn{10}{|l|}{ Grupo etario (años) } \\
\hline$<1$ & 69 & 1 & 1,5 & 7 & 10,1 & 2 & 2,9 & 59 & 85,5 \\
\hline $1-4$ & 54 & 5 & 9,3 & 4 & 7,4 & 4 & 7,4 & 41 & 75,9 \\
\hline $5-10$ & 26 & 4 & 15,3 & 1 & 3,9 & 2 & 7,7 & 19 & 73.1 \\
\hline $11-18$ & 5 & 1 & 20,0 & 0 & 0,0 & 0 & 0,0 & 4 & 80,0 \\
\hline \multicolumn{10}{|l|}{ Sexo } \\
\hline Femenino & 77 & 4 & 5,2 & 8 & 10,4 & 3 & 3,9 & 62 & 80,5 \\
\hline Masculino & 77 & 7 & 9,1 & 4 & 5,2 & 5 & 6,5 & 61 & 79,2 \\
\hline \multicolumn{10}{|l|}{ Año de atención } \\
\hline 2017 & 52 & 4 & 7,7 & 0 & 0,0 & 4 & 7,7 & 44 & 84,6 \\
\hline 2018 & 102 & 7 & 6,9 & 12 & 11,8 & 4 & 3,9 & 79 & 77,5 \\
\hline \multicolumn{10}{|l|}{ Tipo de atención } \\
\hline Hospitalización & 118 & 5 & 4,2 & 11 & 9,3 & 6 & $5 ., 1$ & 96 & 81,4 \\
\hline Emergencia & 27 & 5 & 18,5 & 1 & 3,7 & 2 & 7,4 & 19 & 70,4 \\
\hline Consultorio & 9 & 1 & 11,1 & 0 & 0,0 & 0 & 0,0 & 8 & 88,9 \\
\hline \multicolumn{10}{|l|}{ Estacionalidad } \\
\hline Verano & 16 & 3 & 18,7 & 0 & 0,0 & 0 & 0,0 & 13 & 81,3 \\
\hline Otoño & 84 & 6 & 7,1 & 2 & 2,4 & 0 & 0,0 & 76 & 90,5 \\
\hline Invierno & 39 & 0 & 0,0 & 0 & 0,0 & 7 & 17,9 & 32 & 82,1 \\
\hline Primavera & 15 & 2 & 13,3 & 10 & 66,7 & 1 & 6,7 & 2 & 13,3 \\
\hline \multicolumn{10}{|l|}{ Patología de base } \\
\hline EC. aparato respiratorio & 7 & 1 & 14,3 & 2 & 28,6 & 0 & 0,0 & 4 & 57,1 \\
\hline EC. sistema circulatorio & 49 & 4 & 8,2 & 6 & 12,2 & 1 & 2,0 & 38 & 77,6 \\
\hline EC. sistema nervioso & 7 & 0 & 0,0 & 1 & 14,3 & 0 & 0,0 & 6 & 85,7 \\
\hline MC. tracto digestivo & 8 & 0 & 0,0 & 2 & 25,0 & 1 & 12,5 & 5 & 62,5 \\
\hline $\begin{array}{l}\text { MC. Sistema osteomus- } \\
\text { cular }\end{array}$ & 5 & 0 & 0,0 & 0 & 0,0 & 0 & 0,0 & 5 & 100,0 \\
\hline E. sistema nervioso & 10 & 0 & 0,0 & 0 & 0,0 & 2 & 20,0 & 8 & 80,0 \\
\hline $\begin{array}{l}\text { Neoplasia maligna hema- } \\
\text { tológica }\end{array}$ & 29 & 3 & 10,3 & 0 & 0,0 & 3 & 10,3 & 23 & 79,3 \\
\hline TPH-TOS & 7 & 1 & 14,3 & 0 & 0,0 & 1 & 14,3 & 5 & 71,4 \\
\hline Otras enfermedades & 21 & 2 & 9,5 & 1 & 4,8 & 0 & 0,0 & 18 & 85,7 \\
\hline Ninguna previa & 11 & 0 & 0,0 & 0 & 0,0 & 0 & 0,0 & 11 & 100,0 \\
\hline \multicolumn{10}{|l|}{ Diagnóstico clínico } \\
\hline Rinofaringitis & 8 & 0 & 0,0 & 1 & 12,5 & 1 & 12,5 & 6 & 75,0 \\
\hline Influenza & 5 & 0 & 0,0 & 0 & 0,0 & 1 & 20,0 & 4 & 80,0 \\
\hline Crisis asmática & 3 & 1 & 33,0 & 0 & 0,0 & 0 & 0,0 & 2 & 66,7 \\
\hline Bronquiolitis & 36 & 3 & 8,3 & 0 & 0,0 & 1 & 2,8 & 32 & 88,9 \\
\hline Neumonía viral & 49 & 1 & 2,0 & 7 & 14,3 & 2 & 4,1 & 39 & 79,6 \\
\hline IRA no especificada & 53 & 6 & 11,3 & 4 & 7,5 & 3 & 5,7 & 40 & 75,5 \\
\hline
\end{tabular}

IRA: infección respiratoria aguda; VR: virus respiratorio; E: enfermedad; EC: enfermedad congénita; MC: malformación congénita, TOS: trasplante de órganos sólidos; TPH: trasplante de progenitores hematopoyéticos. 


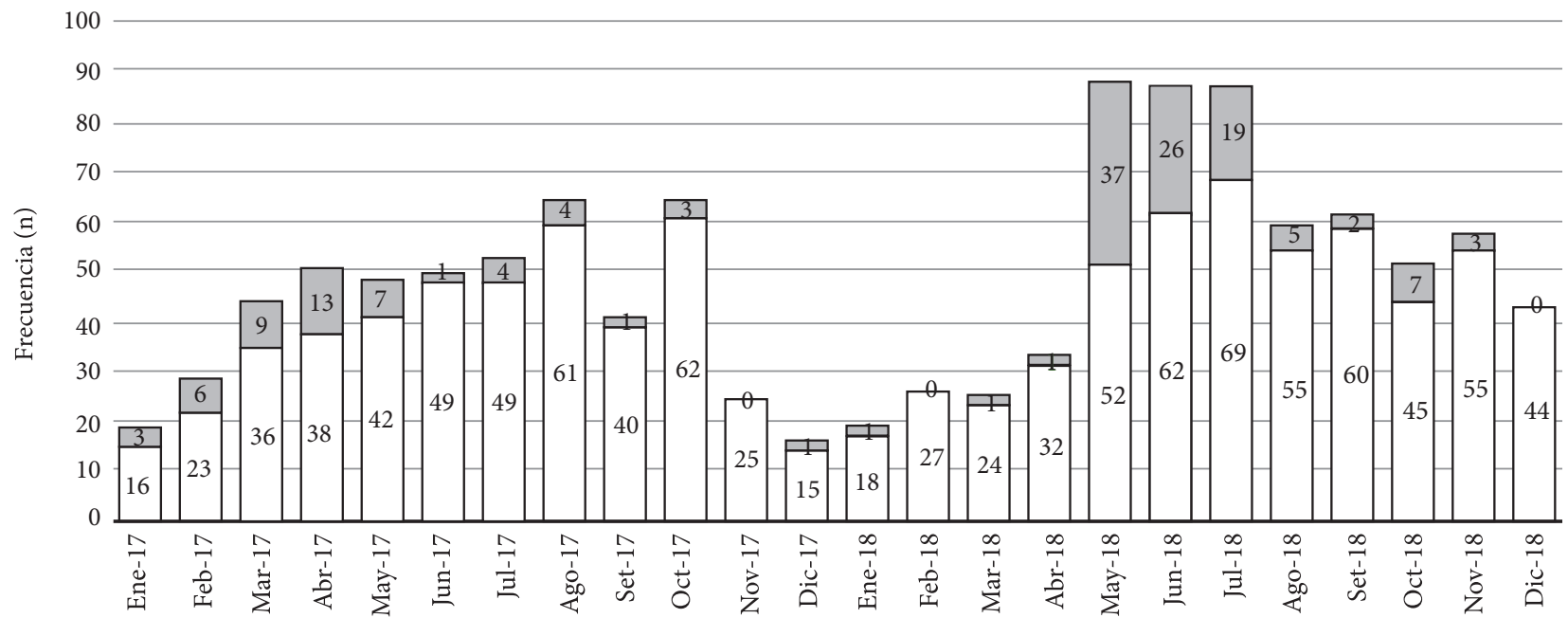

$\square$ Episodios sin detección viral

Episodios con detección viral

Figura 1. Distribución de los 1153 episodios de IRA durante los meses del 2017 y 2018, según la detección viral.

grande de aquellas patologías. El hallazgo de VRS en los casos con EC-SC (13,1\%) fue similar a lo reportado previamente ${ }^{(15,16)}$; mientras que en $\mathrm{NH}$, la frecuencia viral $(6,3 \%)$ fue menor en comparación a otros estudios (7\% a 42\%) ${ }^{(17)}$; en la unidad de cuidados intensivos neonatal no se registró ninguna detección viral en comparación con un estudio que reportó un $47 \%$ de infección ${ }^{(18)}$.

El presente estudio se llevó a cabo utilizando un panel de detección para los principales virus causantes de IRA, un número considerablemente grande de episodios de IRA, incluyendo todas las edades pediátricas, casos hospitalizados como ambulatorios, con diferentes patologías preexistentes y durante un periodo de 2 años, permitiendo evaluar tendencias estacionales.

Dentro de las limitaciones del estudio se debe mencionar: sesgos de selección, probablemente ante la consulta médica se escogió al grupo de pacientes más enfermos, no hubo un criterio estandarizado para determinar a qué pacientes se les realizaba la prueba de IFD para VR. Sesgos en la detección, es posible que aquellos pacientes con infecciones más tempranas sean los únicos que hayan podido ser identificados, mientras que en aquellos con infecciones con una evolución mayor a siete días no se haya podido identificar el agente causante. Los resultados no pueden ser extrapolados a la comunidad. No se pudo determinar el tiempo de evolución de la enfermedad, debido a que la información de fecha de inicio de síntomas fue incompleta en algunos casos. No se evaluó a otros VR frecuentes, como rinovirus y coronavirus (detección por RT-PCR), lo cual conllevó probablemente a la obtención de una menor frecuencia viral.
En conclusión, la frecuencia de VR estuvo relacionada con la edad, la estacionalidad y la patología preexistente, siendo el VRS el principal patógeno. El presente estudio contribuye a un mayor conocimiento de la caracterización de las IRA en los pacientes pediátricos, especialmente en aquellos con enfermedades preexistentes.

Se considera conveniente realizar estudios que permitan caracterizar las infecciones respiratorias virales en pacientes pediátricos con diferentes comorbilidades, que incluya la detección de otros virus frecuentes, teniendo en cuenta el tiempo de evolución de la enfermedad. Asimismo, se debe realizar estudios que permitan identificar los factores de riesgo asociados a la infección respiratoria viral en niños con patologías preexistentes.

Agradecimientos: Los autores expresan su agradecimiento a la Dra. María Medina P. por la revisión del proyecto e informe final, a la Dra. Emiliana Rizo-Patrón T. por la asesoría para el análisis estadístico, a los Dres. Carla Méndez-Chacón R. y Carlos Jamieson V. por la revisión del proyecto, al Tec. Lab. Claudio Vega L. por su apoyo para la obtención de datos y al Ing. Jimmy Vásquez R. y a su equipo de trabajo por permitir la revisión de las historias clínicas.

Contribución de los autores: YCS participó en la concepción y diseño del artículo; análisis e interpretación de datos, redacción del artículo; revisión crítica del artículo. RRG participó en la concepción y diseño del artículo; recolección de datos. EAH participó en la concepción y diseño del estudio. CSS participó en el análisis e interpretación de datos y revisión crítica del artículo. Todos los autores participaron en la aprobación de la versión final del artículo.

Financiamiento: El presente trabajo de investigación fue autofinanciado.

Conflictos de interés: Ninguno de los autores tiene conflictos de interés. 


\section{REFERENCIAS BIBLIOGRÁFICAS}

1. Foro delas Sociedades Respiratorias Internacionales. El impacto global dela Enfermedad respiratoria - segunda edición [Internet]. Mexico: Asociación Latinoamericana de Tórax; 2017 p. 9, 18-21 [citado el 21 de enero de 2019] Disponible en: https://www.who.int/gard/publications/The_Global_Impact_of_Respiratory_Disease_ES.pdf.

2. Organización Mundial de la Salud. Neumonía [Internet]. Ginebra: OMS; 2020 [citado 9 de noviembre de 2020]. Disponible en: https://www. who.int/es/news-room/fact-sheets/detail/pneumonia\#: :text=La\%20 neumon\%C3\%ADa\%20es\%20la\%20principal,a\%C3\%B1os\%20en\%20 todo\%20el\%20mundo.

3. Juy E, Céspedes E, Rubal A, Maza A, Terán C. Morbilidad por infecciones respiratorias agudas en menores de 5 años. MEDISAN 2014;18(11):1490-8.

4. European Respiratory Society. Acute lower respiratory infections [Internet]. European Lung White Book [citado 8 de noviembre de 2020]. Disponible en: https://www.erswhitebook.org/chapters/acute-lower-respiratory-infections/.

5. Ministerio de Salud. Boletín epidemiológico del Perú, volumen 27 - SE 52 [Internet]. Lima: Dirección General de Epidemiología, MINSA; 2018 [citado 19 de noviembre de 2020]. Disponible en: https://www.dge.gob.pe/ portal/docs/vigilancia/boletines/2018/52.pdf.

6. Ge X, Han Z, Chen H, Cheng J, Gao M, Sun H. Characterization of acute respiratory infections among 340 infants in Wuxi, Jiangsu Province. Ann Transl Med. 2015;3(18):264. doi: 10.3978/j.issn.2305-5839.2015.10.23.

7. Spano A, Lamantía E, Terán L, Daniele R, Sanchez L, Cabral M. Inmunofluorescencia indirecta versus Reacción de cadena de la polimerasa en tiempo real para la detección de Virus respiratorios. Rev Bioanálisis. 2019; 15(91):8-18

8. Marcone DN, Carballal G, Ricarte C, Echavarría M. Diagnóstico de virus respiratorios utilizando un sistema automatizado de PCR múltiples (FilmArray) y su comparación con métodos convencionales. Rev Argent Microbiol. 2015;47(1):29-35. doi: 10.1016/j.ram.2014.12.003.

9. Wong-Chew RM, Espinoza MA, Taboada B, Aponte FE, Arias-Ortiz MA, Monge-Martínez J, et al. Prevalence of respiratory virus in symptomatic children in private physician office settings in five communities of the state of Veracruz, Mexico. BMC Res Notes. 2015;8:261. doi: 10.1186 / s13104-015-1239-0.
10. Del Valle J, Cornejo-Tapia A, Weilg P, Verne E, Nazario-Fuertes R, Ugarte C et al. Incidence of respiratory viruses in peruvian children with acute respiratory infections. J Med Virol. 2015;87(6):917-24. doi: 10.1002 / jmv.24159.

11. Mezarina-Esquivel H, Bada-Mancilla C, Castañeda-Campozano R. Identificación viral en pacientes hospitalizados por infecciones respiratorias bajas, en menores de 5 años, en el hospital de emergencias pediatricas. Lima - Perú, 2014. Rev Peru Investig Materno Perinat. 2017;6(2):9-12. doi: 10.33421/inmp.201790.

12. Wang $\mathrm{H}$, Zheng $\mathrm{Y}$, Deng J, Wang W, Liu P, Yang F, et al. Prevalence of respiratory viruses among children Hospitalized from respiratory infections in Shenzhen, China. Virol J. 2016;13(39). doi: 10.1186 / s12985-016-0493-7.

13. Becerra M, Fiestas V, Tantaleán J, Mallma G, Alvarado M, Gutiérrez V, et al. Etiología viral de las infecciones respiratorias agudas graves en una unidad de cuidados intensivos pediátricos. Rev Peru Med Exp Salud Publica. 2019;36(2):231-8. doi: 10.17843/rpmesp.2019.362.4081.

14. Medrano López C, García-Guereta Silva L. Infecciones respiratorias y cardiopatías congénitas: dos estaciones del estudio CIVIC. An Pediatría. 2007;67(4):329-36. doi: 10.1016/S1695-4033(07)70650-1.

15. Sahan Y, Kulıçoğlu E, Tutar Z. Evaluation of Children with Congenital Heart Disease Hospitalized with the Diagnosis of Lower Respiratory Tract Infection. J Pediatr Res. 2018;5(1):32-6. doi: 10.4274/jpr.90532.

16. Resch B, Kurath-Koller S, Hahn J, Raith W, Köstenberger M, Gamillscheg A. Respiratory syncytial virus-associated hospitalizations over three consecutive seasons in children with congenital heart disease. Eur J Clin Microbiol Infect Dis. 2016;35(7):1165-9. doi: 10.1007/s10096-016-2649-1.

17. Saavedra-Lozano J, Garrido C, Catalán P, González F. Niños con cáncer e infección viral respiratoria: epidemiología, diagnóstico y posibles tratamientos. Enfermedades Infecc Microbiol Clínica. 2011;29(1):40-51. doi: 10.1016/j.eimc.2010.04.011.

18. Moreno Parejo C, Morillo García A, Lozano Domínguez C, Carreño Ochoa C, Aznar Martín J, Conde Herrera M. Brote por virus respiratorio sincitial en la Unidad de Neonatología de un hospital de tercer nivel. An Pediatría. 2016;85(3):119-27. doi: 10.1016/j.anpedi.2015.10.002. 